\title{
The Reform of Chemistry Technology Course System Based on Simulation Technology
}

Bin Zhang, Jianzhang Zhao

Office of Teaching Affairs, Xinjiang Institute of Engineering, Urumqi 830091, Xinjiang, China.

Fund Project: 2020 Xinjiang Uygur Autonomous Region Scientific Research Plan: Numerical Simulation and Parameter Optimization of Oil Shale High Density Heavy Medium Cyclone (Project No.: XJEDU2020Y042)

\begin{abstract}
By analyzing the textbooks of various versions of chemical technology and the actual situation of our college, we have integrated the relevant courses and practical links of chemical technology and chemical design, and formed the teaching model of "practice-theory-practice-theory-practice-practice". The application of simulation technology to the course system has formed the characteristic chemistry process course system.

Keywords: Simulation; Chemical Process; Aspen plus

Chemical Process and Chemical Design are two important professional courses in Chemical Engineering and Process. They are all courses that use the knowledge learned in the previous three years to solve practical problems. At the same time, they are also the necessary knowledge base for chemical-related work after graduation. Combined with the training goals of application-oriented talents and the current status of chemical engineering and process majors, it is necessary to reorganize the knowledge of Chemical Process and Chemical Design, as well as related courses and practice systems to form a characteristic application-oriented chemical process course system.
\end{abstract}

\section{Characteristics and teaching status of chemical technology-related courses}

Chemical technology is a subject that studies the principles, methods, processes and equipment of chemical processing to produce chemical products. There are more than 6 million chemicals in the world, and this course cannot cover all chemicals. Different versions of chemical process textbooks use different typical chemicals, and their content organization forms are different. Compiled by Shucai Guo and others, Coal Chemical Technology is a national higher education "12th Five-Year" undergraduate national planning textbook, and won the first prize of China Petroleum and Chemical Industry Excellent Textbook Award, which introduces the knowledge of coal resources, coal low temperature retorting, coking production principles, production methods, process calculations, and operating conditions of recovery and refining of coking chemical products, coal gasification, indirect coal liquefaction, direct coal hydrogenation and liquefaction, coal-to-carbon products, pollution and prevention of coal chemical production, and the main equipment, etc. which are basically organized according to the sequence of low-temperature coal distillation, coking, gasification and liquefaction processing.

In summary, the above textbook selects typical processes according to the actual situation. Except for Inorganic Chemical Technology edited by Wuping Chen, the content is basically based on the reaction principle (including catalyst), process conditions, reaction equipment, process flow, etc. The details of the process are rarely involved. Although various schools have adopted CAI courses made with PowerPoint, AutoCAD, Flash, etc. to show the internal structure and working conditions of the equipment to students in a straightforward and vivid way, thereby greatly increasing students' interest in learning, but students' understanding of the process is difficult to meet expectations

Copyright (C) 2020 Bin Zhang et al.

doi: 10.18282/le.v9i5.1264

This is an open-access article distributed under the terms of the Creative Commons Attribution Non-Commercial License

(http://creativecommons.org/licenses/by-nc/4.0/), which permits unrestricted non-commercial use, distribution, and reproduction in any medium, provided the original work is properly cited. 
purpose.

In addition, the chemical design courses offered by our college also have problems: on the one hand, the content is difficult for the students, and it is boring, resulting in poor teaching effects; on the other hand, the course deviates from the professional training goals of our college. Therefore, the course became "chicken ribs".

\section{Reform of the chemical technology course system}

Based on the above problems, our college integrates the two theoretical courses and related practice links of Chemical Process and Chemical Design to form a characteristic application-oriented chemical process course system.

\subsection{Selection of course content}

Combined with the social and economic development of Xinjiang and the realities of the chemical industry, as well as the academic advantages of our college, we selected typical processes such as synthesis gas preparation and purification, methanol synthesis, ammonia synthesis, urea, and chlor-alkali (acetylene) as the teaching content, and used the integration of industry and education to obtain non-secret PI drawings from enterprises to enrich the teaching resource library.

\subsection{Change of teaching methods}

Since 2008, our college has purchased simulation software such as synthetic ammonia (gas production, purification, synthesis), methanol synthesis and refining, coal water slurry gasification, etc., and has accumulated a wealth of simulation teaching experience and materials, and published a textbook. Combining these advantages, the traditional teaching method of chemical technology is changed, and the teaching model of "practice-theory-practice-theorypractice-practice" is implemented.

First of all, not starting from theoretical teaching, but the law of cognition, to give students a perceptual understanding of the process through process simulation operation. At this stage, the quality of the operation is not required, and a preliminary understanding of the process is required.

The second step is to explain the process principle, equipment function and chemical control in detail in combination with the simulation process, and complete PI drawings. Through this stage, students will master the role of equipment and the control process of each control loop (especially manipulated variables and disturbances).

The third step is the simulation practice. Operate on the basis of a deep understanding of the process, solve the problems encountered during the operation through analysis, gradually improve the quality of the operation, and deepen the further understanding of the process.

The fourth step is theoretical expansion. On the basis of the simulation process, expand other production processes, such as different reactions, different separation processes, different raw materials, etc., and analyze the characteristics of their respective processes. Combined with the technological progress of the chemical industry, lectures on new technologies, new processes and new control methods, especially the application of energy-saving technologies. This stage is the stage of improving the knowledge and ability of students, to achieve the transition from typical to general, students can draw inferences from the examples.

The fifth step is to practice simulation. Change the theoretical teaching of chemical engineering design courses, using Aspen Plus, Aspen Plus Dynamics, Aspen Energy Analyzer, Aspen Process Economic Analyzer and other software to simulate the process involved. Aspen Plus can simulate different process routes. By designing the process flow by themselves, students can understand the process flow more deeply, especially the role of each key equipment (by the material composition of the entry and exit equipment), and also master the basic process design principles and methods. In addition, various energy-saving processes and new processes can be simulated to master the cutting-edge technological essentials. Aspen Plus Dynamics can simulate the control effect of different control methods of the same process. It can intuitively reflect the dynamic process under different interference. Aspen Energy Analyzer can analyze the "pinch point" of the process and optimize the process, so that the incomprehensible "pinch point" technology is intuitively presented. Aspen Process Economic Analyzer can carry out technical and economic analysis, and solve the blind spots of knowledge of Chemical Technology Economics through simulation. In this way of hands-on practice, 
students not only master difficult theoretical knowledge, but also acquire modern design methods, making graduates more competitive in employment.

The sixth step is production internship. Conduct more in-depth and meticulous study and research on a certain section or workshop in production, including the debugging of processes, equipment and operating conditions, and the elimination of simple faults, etc., and finally achieve the unity of theory and practice, and enable students to apply engineering concepts, theoretical knowledge to comprehensively analyze and solve actual production problems, with certain hands-on skills and troubleshooting abilities.

\subsection{Changes in assessment methods}

Change the traditional theoretical examination method, that is, to determine the student's score through a test paper ignoring the theoretical assessment, implement a combination of multiple assessment methods, and a comprehensive evaluation method. The final score is composed of simulation exercises (40\%), PI chart drawing (10\%), simulation exercises (10\%), answering sessions (20\%), and in-process performances $(20 \%)$.

\section{Conclusion}

On the basis of the textbooks of analytical chemical processes, combined with the local economic development and the actuality of the chemical industry, as well as the teaching practice of our college, we reformed the course content, teaching methods, and assessment methods, and reorganized the relevant courses and practice links to form The "practice-theory-practice-theory-practice-practice" teaching mode. The school also applies simulation software, Aspen Plus, Aspen Plus Dynamics, Aspen Energy Analyzer, Aspen Process Economic Analyzer and other software to the teaching, forming a distinctive applied chemistry course system. This teaching system is in line with the school's talent training orientation, as well as the training goals of the chemical engineering and technology majors and the needs of job positions, which provides an important exploration for the reform of the curriculum system for the training of application-oriented chemical engineering and technology majors.

\section{References}

1. Gao Y, Song L. The requirements of chemical production on the quality and technology of total control workers. Chlor-Alkali Industry 2020; 56(03): 43-45.

2. Mi Z. Chemical Technology (2nd Edition). Chemical Industry Press; 2014.

3. Sun L, Liu X, Chen D, et al. Thinking and practice of chemistry technology teaching for "Excellence Project". Higher Education in Chemical Engineering 2016; 33(03): 24-26.

4. Zuo X, Liu B, Deng X, et al. Teaching discussion on Inorganic Chemical Technology. Journal of Hubei Institute of Technology 2008; 24(5): 68-70.

5. Guo S, Hu H. Coal Chemical Technology (3rd Edition). Chemical Industry Press; 2012. 